\title{
Are camouflaged seeds less attacked by wild birds?
}

\author{
Alexandre de Almeida ${ }^{1}$; Hilton Thadeu Zarate do Couto ${ }^{2 *}$; Álvaro Fernando de Almeida ${ }^{2}$ \\ ${ }^{1}$ UFBA/IB - Depto. de Zoologia, Laboratório de Vertebrados Terrestres, R. Barão de Geremoabo, s/n - 40170-115 \\ - Salvador, $B A-$ Brasil. \\ ${ }^{2}$ USP/ESALQ - Depto. de Ciências Florestais, C.P. 9 - 13400-970 - Piracicaba, SP - Brasil. \\ *Corresponding author <htzcouto@esalq.usp.br>
}

\begin{abstract}
Wheat, corn and rice crops in Brazil use seeds treated with systemic insecticide/nematicide carbofuran, mixed to rhodamine B red dye. Carbofuran is toxic and rhodamine B is attractive to wild birds that eat up these seeds, resulting in notable mortality during planting. A field experiment was performed in southeast Brazil to evaluate if camouflaged seeds would be less consumed by wild birds in comparison to commercial seeds with red-colored rhodamine B and aposematic blue seeds. Camouflaged seeds were less removed than seeds with rhodamine $B$ and natural colors. The camouflaging was more effective in the presence of irregularities and litter. There was no removal of blue-colored seeds. As legislation requires treated seeds to receive a different color to avoid accidents with humans, camouflaging may be used as replacement of rhodamine B to reduce mortality rates of wild birds.
\end{abstract}

Key words: seed camouflage, carbofuran, rhodamine B, visual repellents, bird mortality

\section{Sementes camufladas são menos atacadas por aves silvestres?}

\begin{abstract}
RESUMO: Plantações de trigo milho e arroz no Brasil utilizam sementes tratadas com o inseticida e nematicida sistêmico carbofuran, associado ao corante vermelho rodamina B. O carbofuran é tóxico e a rodamina B é atrativa às aves silvestres, as quais consomem estas sementes, resultando em notável mortalidade durante o plantio. Um experimento realizado em campo agrícola no sudeste do Brasil mostrou que sementes camufladas foram menos removidas por aves silvestres do que sementes com rodamina B. A camuflagem foi potencializada em presença de irregularidades e serrapilheira no solo. Não houve remoção de sementes de cor azul, mas a formulação granular de cor azul tem causado mortalidade de aves nos USA e Canadá. Como sementes tratadas com agrotóxicos devem, de acordo com a legislação, receber coloração diferenciada para evitar acidentes com humanos, a camuflagem pode ser utilizada, substituindo a rodamina B.

Palavras-chave: camuflagem de sementes, carbofuran, rodamina B, repelentes visuais, mortalidade de aves
\end{abstract}

\section{Introduction}

Treatment of wheat, rice and corn seeds with carbofuran, carbosulfan and pyrethroids has been used to protect against soil pests and according to the Brazilian Federal Decree $\mathrm{n}^{\circ} 4074$ from January 4, 2002, systemic defensives must be added to the seeds in association with dyes, thus reducing the risk of ingestion by humans. Rhodamine B is widely used as dye in treated seeds, and its reddish-purple hue contrasting with the soil is conspicuous to the wild birds (Hartley et al., 2000; Schmidt et al., 2004).

As treated seeds may not be properly buried at sowing, they represent a potential food source for granivorous birds, causing direct mortality by deliberate ingestion of seeds or by secondary intoxication in predators and scavengers through ingestion of poisoned fauna. Studies have targeted finding chemical repellents and or aversive colors for reducing the damage on production and decreasing the poisoning risks for the wild fauna (Tobin, 2002; Avery, 2002). Actually Hartley et al. $(1999,2000)$ tested with relative success the use of potentially aversive blue and brown dyes to reduce consumption of poisoned grains by birds.
Cryptic behavior and camouflaging are evolutionary adaptations which decrease detection chances for a species, whose color or shape are similar to common aspects in the environment where they live (Zug et al., 2001; Merilaita, 2003). Conversely, the use of attractive colors, indicating warning or notice, to reduce bird attacks, is based in the aposematism theory, in which a color conspicuous of warning helps to prevent attacks, because they are signals to the predator that the prey is not so good (Härlin and Härlin, 2003; Thomas et al., 2004).This study aimed at evaluating if camouflaged seeds would be less consumed by wild birds in comparison to commercial seeds coated with red-colored rhodamine B and blue seeds (Avery et al., 1999; Hartley et al., 1999, 2000).

\section{Material and Methods}

Seed removal experiments were performed in April 2002 and in July 2005 in an area reserved for annual plant-

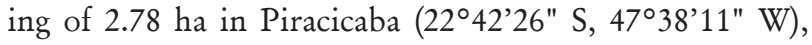
State of Sao Paulo, Brazil. Because of the frequent planting of corn and other cultures, a great deal of granivorous birds could be found at the site, contrary to the other 
animals which could bias the experiment, like ants, controlled with pesticides, and mammals, controlled by fences and pesticides. The most abundant granivorous birds in the area were the domestic pigeon Columba livia Gmelin, the shiny-cowbird Molotbrus bonariensis (Gmelin), the eared dove Zenaida auriculata (Des Murs), the picazuro pigeon Patagioenas picazuro (Temminck), the ruddy ground dove Columbina talpacoti (Temminck), and the ruffous-collared sparrow, Zonotrichia capensis (Statius Muller).

Experimental plots $(1.5 \times 1.5 \mathrm{~m})$ delimited by four poles and nylon thread were randomly distributed in the area circa $50 \mathrm{~m}$ from each other. Seeds from each treatment were distributed in columns on the ground approximately $11 \mathrm{~cm}$ apart (Figure 1). Daily samplings were taken (12h00) for six days after setup, checking the number of remaining seed in these periods. Replacement of removed seeds was done only in one trial because wheat and rice seeds are easily destroyed when exposed to the weather.

Camouflages tested corresponded to the treatments created with the ingredients: liquid dye and powder dye, both colored brown and/or terracotta. The brown-colored powder dye was shaded and thus adjusted by comparison to soil samples from the area. The camouflaged coating elicited by powder dye gave the seeds a dark brown, rugged and opaque surface.

The brown-colored liquid dye was a novel product which attributed to the seeds a smooth, opaque coating, with a shade slightly lighter than the soil in the experiment location. Acrylic glue was added to the dye to enhance adhesion and resistance to camouflaging. Dye and glue were applied to seed as an aqueous solution. Soil of the trials' site was tested as a substitute to artificial

$1.5 \mathrm{~m} \mid$\begin{tabular}{lllllll}
1 & \multicolumn{1}{c}{$25 \mathrm{~cm}$} \\
1 & 2 & 3 & 4 & 5 & 6 & 7 \\
1 & 2 & 3 & 4 & 5 & 6 & 7 \\
1 & 2 & 3 & 4 & 5 & 6 & 7 \\
1 & 2 & 3 & 4 & 5 & 6 & 7 \\
1 & 2 & 3 & 4 & 5 & 6 & 7 \\
1 & 2 & 3 & 4 & 5 & 6 & 7 \\
1 & 2 & 3 & 4 & 5 & 6 & 7 \\
1 & 2 & 3 & 4 & 5 & 6 & 7 \\
1 & 2 & 3 & 4 & 5 & 6 & 7 \\
1 & 2 & 3 & 4 & 5 & 6 & 7 \\
1 & 2 & 3 & 4 & 5 & 6 & 7 \\
& \multicolumn{1}{c}{$1.5 \mathrm{~m}$} \\
1
\end{tabular}

Figure 1 - Plot from experiment one of corn seed removal, where: 1 - natural undyed corn; 2 - corn with rhodamine B; 3 - corn camouflaged with powder dye and water; 4 - corn camouflaged with powder dye, glue and water; 5 - corn camouflaged with powder dye and water; 6 - corn camouflaged with powder dye, water, glue and soil; 7 - corn camouflaged with water, glue and soil. dyes and/or as an accessory camouflaging element, aiming for a higher coincidence in shades of camouflaging colors in relation to the soil.

Camouflages were applied onto seeds with either natural or purplish-red colors, previously treated with rhodamine B dye, the product ordinarily and legally used in Brazil to distinguish pesticides-treated seeds. For that reason, only seed removals dyed with rhodamine B were evaluated.

To evaluate the effect of the search image (Begon et al., 2006) of birds for non-dyed, natural grains in comparison to the other treatments, ordinary corn seeds were also used to mimic the situation wild birds find in harvest wastes. Finally, to evaluate the possible aposematic or neophobic effect of blue color, seeds were treated with mid-blue powder dye.

None of the tested treatments had pesticides. Variance analyses of the daily seed permanence in the trials were performed by the Kruskal-Wallis $(\mathrm{H})$ test and Student-Newman-Keuls post test.

Trial 1 - To evaluate camouflaged corn seed remaining, natural and rhodamine B-colored, twelve squares with seven rows of seeds each were distributed. Five types of brown camouflage treatments were tested, natural undyed corn and corn with rhodamine B only (Figure 1). The soil under five parcels was weeded and leveled to elicit studying the influence of irregularities and litter on seed removal. The yellow corn grain (natural) and rhodamine B-treated corn columns (columns one and two) could be more attractive to the birds, possibly exposing columns close to groups one and two to higher pressure than those more distant. For that reason, the order of columns was modified in each parcel so that all treatments could bear the same influence of closeness to the control groups (Figure 2).

Trial 2 - The differences in the permanence of wheat, corn and rice seeds with the following treatments were evaluated: i) natural, undyed seeds; ii) rhodamine Btreated seeds; ii) brown powder dye-camouflaged seeds; iv) industrialized camouflage with liquid brown dye; v) seeds camouflaged with mid-blue powder dye. Permanence differences among treatment (colors) and botanical species were also evaluated in twelve experimental parcels (four parcels per grain species). All the parcels were weeded and leveled for making the counting of smaller seeds (wheat and rice) more accurate. Because columns with natural colors, blue or rhodamine B could be more attractive to birds, the order of the columns was changed in each parcel, exposing the camouflage treatments to influences identical to the closeness to groups with attractive colors, similar to that represented in Figure 2.

\section{Results and Discussion}

In Trial 1, averages of remaining seeds at one, three and five days of trial suggest that undyed (yellow) and 
red-colored (rhodamine $\mathrm{B}$ ) seeds were more attractive to birds (Table 1). The heterogeneity among seed consumption averages was accentuated with time, reflect-

\begin{tabular}{llllllll}
\hline $\mathbf{1}$ & $\mathbf{2}$ & 3 & 4 & 5 & 6 & 7 & Parcel 1 \\
\hline 3 & $\mathbf{1}$ & $\mathbf{2}$ & 4 & 5 & 6 & 7 & Parcel 2 \\
\hline 3 & 4 & $\mathbf{1}$ & $\mathbf{2}$ & 5 & 6 & 7 & Parcel 3 \\
\hline 3 & 4 & 5 & $\mathbf{1}$ & $\mathbf{2}$ & 6 & 7 & Parcel 4 \\
\hline 3 & 4 & 5 & 6 & $\mathbf{1}$ & $\mathbf{2}$ & 7 & Parcel 5 \\
\hline 3 & 4 & 5 & 6 & 7 & $\mathbf{1}$ & $\mathbf{2}$ & Parcel 6 \\
\hline $\mathbf{1}$ & $\mathbf{2}$ & 3 & 4 & 5 & 6 & 7 & Parcel 7 \\
\hline 3 & $\mathbf{1}$ & $\mathbf{2}$ & 4 & 5 & 6 & 7 & Parcel 8 \\
\hline 3 & 4 & $\mathbf{1}$ & $\mathbf{2}$ & 5 & 6 & 7 & Parcel 9 \\
\hline 3 & 4 & 5 & $\mathbf{1}$ & $\mathbf{2}$ & 6 & 7 & Parcel 10 \\
\hline 3 & 4 & 5 & 6 & $\mathbf{1}$ & $\mathbf{2}$ & 7 & Parcel 11 \\
\hline 3 & 4 & 5 & 6 & 7 & $\mathbf{1}$ & $\mathbf{2}$ & Parcel 12 \\
\hline
\end{tabular}

Figure 2 - Disposition of treatment columns in corn seed removal experiment one parcels. Treatments are according to Figure 1. ing delay in finding parcels and the higher consumption of undyed and red seeds (Table 1).

Differences in permanence of rhodamine B-treated red seeds in comparison to camouflaged seeds were detected only after the third day (Table 1) usually when the corn seeds germinate in the presence of rain or irrigation, which did not occur. From the third day on, a significant removal of seeds from treatment 'camouflaged with soil, glue and water' happened, as a result of rupture of the coating layer, which exposed the yellow color to the birds. The lowest numbers of removals were found for seeds which camouflage was based on powder dye, water, liquid dye, and acrylic glue (Table 1). The heterogeneity among treatments was higher in weeded and flattened parcels $(\mathrm{H}=410.15$; $\mathrm{df}=6 ; p=$ 0.000 ) in comparison to the heterogeneity obtained in irregular-surfaced parcels $(\mathrm{H}=167.61 ; \mathrm{df}=6 ; p=0.01)$. There was also some heterogeneity on seed removals between weeded and leveled parcels, where the permanence percentage reached $68.29 \%$, in comparison to those with irregular surfaces, in which the measured permanence was $71 \%(\mathrm{H}=55.98$; $\mathrm{df}=1 ; p=0.018)$. Heterogeneity registered among treatments and among par-

Table 1 - Corn seeds permanence at one, three and five days of bird exposure. Percentages refer to the number of remaining seeds in relation to the total seeds in each treatment.

\begin{tabular}{lcccc}
\hline Treatment & Mean & Variance & Total & Percentage \\
\hline Camouflaged with powder dye, glue, water & First day & & & \\
Camouflaged with powder dye, water & $13.8 \mathrm{ab}$ & 0.8 & 165 & 98.2 \\
Camouflaged with powder dye, liquid dye, water & $13.6 \mathrm{ab}$ & 1.4 & 163 & 97 \\
Camouflaged with powder dye, soil, glue, water & $13.3 \mathrm{ab}$ & 3 & 160 & 95.2 \\
\hline Camouflaged with soil, glue and water & $13.3 \mathrm{ab}$ & 4.2 & 159 & 94.6 \\
\hline Red corn rhodamine B & $12.8 \mathrm{bc}$ & 8.6 & 153 & 91.1 \\
\hline Natural yellow corn & $12.2 \mathrm{bc}$ & 18.7 & 146 & 86.9 \\
\hline & $8.1 \mathrm{c}$ & 42.8 & 97 & 57.7 \\
\hline Camouflaged with powder dye, glue, water & Third day & & & \\
Camouflaged with powder dye, water & $12.6 \mathrm{a}$ & 19.9 & 151 & 89.9 \\
Camouflaged with powder dye, liquid dye, water & $12.2 \mathrm{a}$ & 16 & 146 & 86.9 \\
Camouflaged with powder dye, soil, glue, water & $11.8 \mathrm{a}$ & 16.7 & 142 & 84.5 \\
Camouflaged with soil, glue, water & $10.7 \mathrm{ab}$ & 21.3 & 128 & 76.2 \\
Red corn rhodamine B & $6 \mathrm{bc}$ & 33.3 & 72 & 42.9 \\
Natural yellow corn & $5.6 \mathrm{bc}$ & 40.6 & 67 & 39.9 \\
\hline & $3.6 \mathrm{c}$ & 33.5 & 43 & 25.6 \\
\hline Camouflaged with powder dye, glue, water & Fifth day & & & \\
Camouflaged with powder dye, water & $12 \mathrm{a}$ & 19 & 132 & 78.6 \\
Camouflaged with powder dye, liquid dye, water & $11.8 \mathrm{a}$ & 16.8 & 130 & 77.4 \\
Camouflaged with powder dye, soil, glue, water & $11.2 \mathrm{a}$ & 22.4 & 123 & 73.2 \\
Red corn rhodamine B & $9.9 \mathrm{ab}$ & 17.5 & 109 & 64.9 \\
Camouflaged with soil, glue, water & $4.9 \mathrm{bc}$ & 38.5 & 54 & 32.1 \\
\hline Natural yellow corn & $3.9 \mathrm{bc}$ & 28.7 & 43 & 25.6 \\
\hline
\end{tabular}

Means followed by the same letter are not different (Kruskal-Wallis test and Student-Newman-Keuls post test, $p<0.05$ ). 
cels with either regular or irregular surfaces substantiates the fact that soils presenting higher contrast between light and shade influence the seed removal rate, by increasing the effectiveness of camouflage.

Brown seeds were less removed in irregular-surfaced, littered soil, i.e. covered with vegetal organic matter. The absence of search image (Begon et al., 2006) for brown seeds and less conspicuity of these seeds regarding contrast and visual identification of contours (Schmidt et al., 2004; Cuthill et al., 2005) with higher energy consumption for locating seeds in colors similar to the soil, according to optimal foraging theorem (Avery, 2002), seemingly are the reasons for this fact.

The ingestion of small brown grits to help crushing foods is a common behavior of several bird families (Sick, 1997). It is therefore possible that brown-dyed seeds are less removed as a result of a set of factors linked to the camouflaging phenomenon, such as background match, avoiding well defined contours and color contrasts (Merilaita, 2003; Frankel et al., 2004; Schmidt et al., 2004), and not specifically because of the aversion to brown color, as tested by Hartley et al. $(1999,2000)$.

Camouflaged seeds, previously with color shade similarities, differ in terms of nuances with time in the field. Nonetheless, there were no differences on removal rates among camouflaged seeds. Apparently it may not be necessary having major similarities of shades among camouflaged seeds and the soil to prevent higher consumption rates. Such observation is supported by Merilaita and Lind (2005), who concluded that the exact similarity of colors between the prey and the background is neither enough nor necessary to minimize the probability of detection by the predator. Actually, aversions and preferences for food items by birds are related to flavor and appearance of possible foods (Zuberbuehler et al, 2002). The poorly developed gustative sense is a plausible reason for explaining limited results from Avery et al (1998) and Moran (2001), who used chemical repellants in the absence of alternative food sources. Usual sowing methods, such as 'direct planting', where there is a notable presence of non-decomposed vegetal matter on the surface, and the 'traditional planting', when the land is plowed, may positively affect camouflaging.

Table 2 present wheat, corn and rice seed permanence in the third, fifth and sixth days of exposure in trial two. There were no differences on average of seeds permanence among the three botanical species in none of the days. At the first day of exposure, the variance on averages of remaining seeds among treatments was not significant in Kruskal-Wallis model. The higher consumption of yellow corn may be a consequence of the conspicuity of these seeds and the search image of birds being destined to this resource, very abundant at that moment, when the harvested corn was processed close to the experimental site.

There were no differences among treatments: blue, camouflaged with powder dye and rhodamine B. However, only seeds camouflaged with liquid dye were most significantly removed in comparison to blue seeds

Table 2 - Wheat, corn and rice seeds permanence at three, five and six days of bird exposure. Percentages refer to the number of remaining seeds in relation to the total seeds in each treatment.

\begin{tabular}{lcccc}
\hline Treatment & Mean & Variance & Total & Percentage \\
\hline Blue (medium hue) powder dye & First day & & & \\
Camouflaged with brown powder dye & $42 \mathrm{a}$ & - & 504 & 100 \\
Rhodamine B (red) & $41.9 \mathrm{a}$ & 0.1 & 503 & 99.8 \\
Camouflaged with brown liquid dye & $41.1 \mathrm{a}$ & 3.9 & 493 & 97.8 \\
Natural undyed (yellow) & $40.8 \mathrm{ab}$ & 3.1 & 490 & 97.2 \\
\hline & $35.1 \mathrm{bc}$ & 72.4 & 421 & 83.5 \\
\hline Blue (medium hue) powder dye & Fifth day & & & \\
Camouflaged with brown powder dye & $70 \mathrm{a}$ & - & 840 & 100 \\
Rhodamine B (red) & $69.3 \mathrm{ab}$ & 3.5 & 831 & 98.9 \\
Camouflaged with brown liquid dye & $68.1 \mathrm{ab}$ & 9 & 817 & 97.3 \\
Natural undyed (yellow) & $67.1 \mathrm{~b}$ & 22.6 & 805 & 95.8 \\
\hline & $53.8 \mathrm{c}$ & 108.4 & 699 & 83.2 \\
\hline Blue (medium hue) powder dye & Sixth day & & & \\
Camouflaged with brown powder dye & $84 \mathrm{a}$ & - & 1008 & 100 \\
Rhodamine B (red) & $83.3 \mathrm{ab}$ & 3.5 & 999 & 99.1 \\
Camouflaged with brown liquid dye & $81.8 \mathrm{ab}$ & 12.5 & 982 & 97.4 \\
Natural undyed (yellow) & $81.1 \mathrm{~b}$ & 22.6 & 973 & 96.5 \\
\hline
\end{tabular}

Means followed by the same letter are not different (Kruskal-Wallis test and Student-Newman-Keuls post test, $p<0.05$ ). 
(Table 2). These results were similar to those of Trial 1, where seeds camouflaged with liquid dye were also notably attacked (Table 1).

The highest removal of seeds camouflaged with liquid dye show the importance of superficial grooving in the coverage, attributed to the powder dye in the least removed camouflaged seeds in Trials 1 and 2. Thus, the efficiency of the camouflaging is not only characterized by the brown dye, or because of the coincidence of shades between the soil and the seeds, but also by a group of factors attributed to the seed coverage and the background, like opacity and superficial grooving in the seed, besides the presence of irregularities and organic matters on the soil surface.

The absolute absence of blue seeds consumption reinforces the theory that there is aversion to this color, according to Avery et al. (1999) and Hartley et al. (1999, 2000), with the possible occurrence of aposematism (Joron, 2003) and neophobia (Thomas et al., 2004). Nevertheless, the usage of blue-colored granular carbofuran was prohibited in Virginia (USA) in 1991 and in Canada in 1998, because of the mortality of birds caused by the direct ingestion of the product applied to the environment, as high mortality rates of carnivorous and granivorous birds caused by carbofuran have been documented (Eisler, 1985; Agriculture Canada, 1993; Mineau et al., 1999; Mineau, 2005), and many of the control methods tested to keep off undesired birds in agriculture have not brought completely satisfactory results, leading to the spending of high operational and financial resources (Avery and Mason, 1997; Nelms and Avery, 1997; Gill et al. 1998a, b; James et al., 1999; Avery et al., 2001; Moran, 2001), to the disrespect of humane precepts, and causing unnecessary suffering to the birds (Dolbeer et al., 1999; Avery et al., 1998; Sayre and Clarck, 2001).

The seed camouflaging method presents low operational and economic costs, does not cause suffering to birds and may be used to diminish bird's mortality by carbofuran in wheat, corn and rice crops. If seeds treated with pesticides should, according to the legislation, receive a different color to help preventing accidents with humans, camouflaging may be used to replace rhodamine $\mathrm{B}$.

\section{Acknowledgements}

To Ana G. P. Campos, Cristiane de A. Amabilini, Sandra P. Cardoso, Pierre Mineau, Carlos A. Perez, Florindo Orsi Júnior. To the people who allowed studies in ESALQ / USP: Antonio Natal A. Vello, Cláudio Segatelli and to Fersol Industria e Comércio Ltda, for funding this research, as well as all the anonymous revisers.

\section{References}

Agriculture Canada (1993) Special review of carbofuran insecticide: effects on avian fauna and value to agriculture. Ottawa: Plant Industry Directorate, 53p. (Discussion Document D93-02).
Avery, M.L. 2002. Avian reppelents. v.1, p.122-128. In: Plimer, J.R., ed. Encyclopedia of agrochemicals. John Wiley \& Sons, New York, NY, USA.

Avery, M.L.; Tillman, E.A.; Laukert, C.C. 2001. Evaluation of chemical repellents for reducing crop damage by Dickcissels in Venezuela. International Journal of Pest Management 47: 311314.

Avery, M.L.; Humphery, J.S.; Decker, D.G.; McGrane, A.P. 1999. Seed color avoidance by captive red-winged blackbirds and boattailed grackles. Journal of Wildlife Management 63: 1003-1008.

Avery, M.L.; Humphery, J.S.; Primus, T.M.; Decker, D.G.; McGrane, A.P. 1998. Anthraquinone protects rice seed from birds. Crop Protection 17: 225-250.

Avery, M.L.; Mason, J.R. 1997. Feeding responses of red-winged blackbirds to multisensory repellents. Crop Protection 6: 159164.

Begon, M.; Townsend, C.R.; Harper, J.L. 2006. Ecology: From Individuals to Ecosystems. Blackwell, Oxford, UK.

Cuthill, I.; Steves, M.; Sheppard, J.; Maddocks, T.; Párraga, A.C.; Troscianko, T.S. 2005. Disruptive coloration and background pattern matching. Nature 434: 72-74.

Dolbeer, R.A. 1999. Overview and Management of Vertebrate pests. p.663-691. In: Ruberson, J.R., ed. Handbook of vertebrate pest management. Marcel Dekker, New York, NY, USA.

Eisler, R. 1985. Carbofuran hazards to fish, wildlife and invertebrates: a synoptic review. U.S. Fish and Wildlife Service Biological Report 85: 36.

Frankel, K.; Sousa, S.; Cowan, R.; King, M. (2004) Concealment of the warfighter's equipment through enhanced polymer technology in Army Science Conference 24. Proceedings. Orlando: U. S. Army, 13-16.

Gill, E.L.; Watkins, R.W; Cowan, D.P.; Bishop, J.D.; Gurney, J.E. 1998a. Cinnamamide, an avian repellent, reduces woodpigeon damage to oilseed rape. Pesticide Science 52: 159-164.

Gill, E.L.; Feare, C.J.; Cowan, D.P.; Fox, S.M.; Bishop, J.D.; Langton, S.D.; Watkins, R.W.; Gurney, J.E. 1998b. Cinnamamide modifies foraging behaviors of free-living birds. Journal of Wildlife Management 62: 872-884.

Härlin, C.; Härlin, M. 2003. Towards a historization of aposematism. Evolutionary Ecology 17: 197-212.

Hartley, L.; Waas, J.; O’Connor, C.; Matthews, L. 1999. Colour preferences and coloured bait consumption by weka Gallirallus australis: an endemic New Zealand rail. Biological Conservation 93: 255-263.

Hartley, L.; O'Connor, C.; Waas, J.; Matthews, L. 2000. Colour preferences in North Island robins (Petroica australis): implications for deterring birds from poisonous baits. New Zealand Journal of Ecology 23: 255-259.

James, J.B.; Hellgren, E.C.; Masters, R.E. 1999. Effects of deterrents on avian abundance and nesting density in electrical substations in Oklahoma. Journal of Wildlife Management 63: 1009-1017.

Joron, M. 2003. Aposematic coloration. p.39-45. In: Cardé, R.T.; Resh, V.H. Encyclopedia of insects. Academic Press, New York, NY, USA.

Merilaita, S. 2003. Visual background complexity facilitates the evolution of camouflage. Evolution 57: 1248-1254.

Merilaita, S; Lind, J. 2005. Great tits (Parus major) searching for artificial prey: implications for cryptic coloration and symmetry. Behavioral Ecology 17:84-87.

Mineau, P. 2005. Direct losses of birds to pesticides: beginnings of a quantification. USDA Forest Service General Technical Report 2: $1065-1070$.

Mineau, P.; Fletcher, M.R.; Glaser, L.C.; Thomas, N.J.; Brassard, C.; Wilson, L.K.; Elliott, J.E.; Lyon, L.A.; Henny, C.J.; Bolinger, T.; Porter, S.L. 1999. Poisoning of raptors with organophosphorus and carbamate pesticides with emphasis on Canada, U.S., and U.K. Journal of Raptor Research 33: 1-37.

Moran, S. 2001. Aversion of the feral pigeon and the house sparrow to pellets as sprouts treated with commercial formulations of methyl anthranilate. Pest Management Science 57: 248-252. 
Nelms, C.O.; Avery, M.L. 1997. Reducing bird repellent application rates by the additiion of sensory stimuli. International Journal of Pest Management 43: 187-190.

Sayre, R.W.; Clarck, L. 2001. Effect of primary and secondary repellents on European starlings: an initial assessment. Journal of Wildlife Management 65: 461-469.

Schmidt, V.; Schaefer, H.M.; Winkler, H. 2004. Conspicuousness, not colour as foraging cue in plant-animal signaling. Oikos 106: 551-557.

Sick, H. 1997. Ornitologia Brasileira. Nova Fronteira, Rio de Janeiro, RJ, Brazil.

Tobin, M.E. 2002. Developing methods to manage conflicts between humans and birds-three decades of change at the USDA National Wildlife Research Center. In: Proceedings of the Vertebrate Pest Conference. University of California, Davis, CA, USA.
Thomas, R.J.; Bartlett, L.A.; Marples, N.M.; Kelly, D.J.; Cuthill, I.C. 2004. Prey selection by with birds can allow novel and conspicuous color morfhs to spread in prey populations. Oikos 106: $285-294$.

Zuberbuehler, C.A.; Messikommer, R.E.; Wenk, C. 2002. Choice feeding of selenium-deficient laying hens affects diet selection, selenium intake and body weight. Journal Nutritional 132: 34113417.

Zug, G.R.; Vitt, L.J.; Caldwell, J.P. 2001. Herpetology: An Introductory Biology of Amphibians and Reptiles. Academic Press, San Diego, CA, USA.

Received October 02, 2007

Accepted August 13, 2009 